\title{
Agile Corps - A Public Service-Learning Program Part II: Pilot
}

\author{
Victor Udoewa \\ Service Design Lead \& Customer Experience Strategist \\ NASA \\ Washington, D.C. 20546 \\ victor.udoewa@nasa.gov
}

\author{
Andrew Maier \\ Service Designer \\ Government of Alberta \\ Stony Plain, AB T7Z 1W2 Canada \\ andrew.maier@gov.ab.ca
}

\begin{abstract}
Annually, the U.S. government invests \$94 billion on IT products and services. The majority of these projects fail--they are late, over budget, canceled outright, or, if delivered, are outdated or not user-friendly. Due to barriers in hiring and training, the government tends to outsource IT talent at a premium through contractors, but outsourcing talent has not changed the results. Inside the government, the small amount of talent that exists tends to be senior, and there currently are very few, viable options for high-quality, junior and mid-level technologists to find a job in government and professionally develop and progress. Agile Corps is a program designed to identify, recruit, train, and retain junior and mid-level technology talent in the government. Agile Corps exemplifies public service-learning, a learning approach and strategy that combines learning objectives, instruction, and reflection with government service for the public. After completing a discovery research process followed by prototyping and testing the program design, we piloted the Agile Corps program at the US Department of Labor. This paper presents the Department of Labor pilot of Agile Corps and the concept of public service-learning, and measures the impact of the Agile Corps pilot at the Department of Labor.
\end{abstract}

Index Terms - Agile Corps, public-service learning, Human-centered Design, digital services

\section{INTRODUCTION}

Each year the U.S. government invests more than $\$ 86$ billion on IT products and services, yet this does not usually yield solutions that meet the needs of the users of those products and services ${ }^{1-2}$. In fact, $94 \%$ of those IT projects fail, according to the former Deputy Director of the US Digital Services (USDS), Haley van Dyck. "The status quo is failure. " Failure includes a project that is late, over-budget, canceled, or, if delivered, unuseful and unfriendly to the user, or outdated.

One approach to addressing the problem is by changing the culture around software engineering in the government, including a shift to more innovative development methodologies. The White House published a report encouraging innovation and Agile methodologies in government technology work ${ }^{3}$. Another approach is to address the problem from the human resource perspective; however most of the software engineering work is done by contractors outside the government ${ }^{4-5}$. While trying to address this problem, federal government agencies find it difficult to hire quality technology talent, creating a void of skilled people who can implement technology solutions within the government ${ }^{6-7}$. Additionally, agencies struggle or fail to train their existing employees on modern digital practices, which often results in training dollars going unused. Outside the government, individuals with technology talent have a desire to work for the 
federal government, but encounter roadblocks when trying to find a job in the government due to complex hiring processes.

Public civic consultancies named $\underline{18 \mathrm{~F}}$, the $\underline{\mathrm{PIF}}$, and $\underline{\mathrm{USDS}}$, are organizations that represent another model for a solution ${ }^{8-10}$. They have attempted to address this problem by hiring senior designers, product managers, and developers from companies like Amazon and Google, but the government ultimately lacks a way to turn skilled junior and mid-level talent into the skilled senior workers that can help transform the government digital portfolio. How might we increase the number of skilled candidates at all levels who use modern digital practices such as Lean Startup, Human-centered Design (HCD), and Agile mindsets to improve the outcome of government products and services? When hired, how do we keep such workers in government providing them with a pathway for development and growth? These were the questions that fueled the authors in their design research to design, prototype, and test Agile Corps, an educational program designed to build a cadre of skilled junior and mid-level technologists in government with professional growth pathways ${ }^{11}$.

In order to quickly develop individuals into experienced talent that can impact government, Agile Corps was conceptualized, researched, and designed by $18 \mathrm{~F}$ to find, recruit, hire, train, and retain both existing federal employees and external talent with a digital background, by creating a hands-on, experiential, developmental program that enhances the knowledge and skills of participants. Because Agile Corps allows candidates to work on real-world challenges in service of the US public including citizens, refugees, and immigrants, we define a new term called public service-learning. Public service-learning (PSL) is a learning approach and strategy that combines learning objectives, instruction, and reflection with, specifically, public sector or government service on behalf of the public. In PSL, there is an equally mixed purpose of the growth and development of the learner as well as positive outcomes or benefits for citizens, immigrants, and refugees--strengthened public communities. Because service-learning is defined as "a form of experiential education in which students engage in activities that address human and community needs together with structured opportunities for reflection designed to achieve desired learning outcomes," PSL is a form of service-learning ${ }^{12}$.

Public service-learning, however, is more than experiential learning objectives, instruction, and reflection combined with government service to address needs of the public. In contrast to service-learning, PSL occurs within the context of a public sector job. The learning which happens in the context of the jobs of the learners, alters the actions of government workers within a government organization. Because repeated thoughts often become actions and repeated actions become habits and habits that pervade, become culture, PSL alters the culture within public sector agencies $^{13-16}$. A key element of PSL is culture transformation of an organization.

Public service-learning holds two main advantages over traditional service-learning. First, in the PSL model presented in Part I and II of this paper, service projects do not need to be found for the learners because the public sector, adult learners have jobs that inherently contain public service work affecting the public. Because managers tend not to lessen the workloads of team members who are in training, the disadvantage of PSL is scheduling time for the classroom instruction since it must be part of the work day. Second, traditional service-learning can focus on the benefit to the learner, the benefit to the community, or both. As an advantage, PSL has an inherent, inseparable link between the benefit to the learner who is a public sector worker and the benefit to the public. Education that improves the public sector worker's work skills, quality, efficiency or effectiveness automatically improves benefit to the public to which that worker 
International Journal for Service Learning in Engineering, Humanitarian Engineering and Social Entrepreneurship Vol. 16, No. 1, pp. 58-89, Spring 2021

ISSN 1555-9033

contributes. Thus the organizational, culture transformation of PSL leads to transformation or improvement of government products and services for the public.

It is important to differentiate PSL from in-service training. In-service training is professional development or staff training that serves as continuing education. In-service training is shorter in duration than the duration of a PSL program. An in-service training can last a day (in-service day) while PSL is a multi-month, continual program. Second, there can be multiple in-service workshops across a year, but they are not necessarily connected. They are one-time training. In contrast, PSL's multiple sessions, service work, and reflections are all connected and related to improve learning for the participants and outcomes in their public service projects. Most importantly, in-service training has a circumstantial, rather than measured, connection to any possible public service projects. Public Service-Learning uses a tight and measured connection between student learning and outcomes for the public community. In this way, in-service training is an example of "service LEARNING" where the learning is primary; while PSL is an example of "service-learning" where service outcomes and learning outcomes are not only equal but tightly coupled feeding into each other. In-service training tends to measure the learning during the workshop but not after. It does not measure public, community outcomes. Public Service-Learning measures learning and community outcomes and constantly cycles between the two for improved learning and outcomes.

The PSL model is applicable to schools and higher education service-learning programs. First, the PSL model can be applied to public schools and universities because the employees are government employees with public service jobs. Public Service-Learning serves to transform the school and university culture. Second, the PSL model can also be applied to private schools, colleges, and universities; though, more work may or may not be required to find public service projects and partnerships. In both cases, with public and private schools, colleges, and universities, the PSL model becomes a "service-learning as pedagogical training" framework. The PSL model can be employed to train faculty in schools and universities to implement service-learning in their classrooms using an experiential, learning-by-doing approach. Service-learning becomes the culture-transforming training and means through which faculty learn to use service-learning with their students. Third, the PSL model critiques the duration of certain school and university-based service-learning programs by encouraging a multi-month or multi-year model for greater impact and learning. This suggests the creation of service-learning programs that surpass the length of a semester or trimester course and can span an academic year or multiple years.

In order to pilot Agile Corps, we first completed a design process to uncover the needs. In Part I of this paper, an $18 \mathrm{~F}$ design research team conducted discovery research to validate the need for the program and the needs of potential students and government agencies ${ }^{11}$. Through synthesis of the research, the $18 \mathrm{~F}$ team uncovered patterns, themes, insights, and frameworks affecting the problem. After ideating and strategic mapping, the $18 \mathrm{~F}$ team created two prototypes: 1) a one-page description and ad for the program (one-pager), and 2) a longer two-page description with a bit more information (two-pager), a pitch presentation, and a 6-month syllabus and educational plan. After testing with various agencies through multiple iterations, five major features of the prototype design changed: the number and type of academic tracks, the weekly time commitment, the duration, the location, and the cohort composition. By the end of the first major design phase, the unpiloted Agile Corps concept was a national, US-based, PSL program involving synchronous and asynchronous education consisting of 6 tracks (design, software engineering, security, product management, data science, mixed) for a 3-6 month duration, meeting for a few hours a day, a few 
days a week, for a mixed cohort of students ${ }^{11}$. The mixed cohort was intended to be $50 \%$ internal government participants and 50\% external participants hired into government. Certain features were flexible. An agency could choose any number of tracks, an in-person experience or a fully remote program, and $100 \%$ internal government employees or $100 \%$ new hires.

The $18 \mathrm{~F}$ design team then continued to market the revised syllabus, one-pager, two-pager, and pitch deck to various agencies to see if any would purchase a pilot. The Environmental Protection Agency (EPA) began talks with the 18F design team to purchase the software engineering track. The Department of Treasury Office of Financial Research (OFR) began contract negotiations with $18 \mathrm{~F}$ for the design track for a cohort of their employees. However, the first agency to purchase and host a pilot was the Department of Labor (DOL). The Wage and Hour Division (WHD) of DOL purchased a 3-month, mixed program for $\$ 256,000$. They were the first and only agency to request a mixed track where participants learn to apply HCD, Lean Startup, and Agile to their job regardless of the function, engineering or non-engineering (i.e. finance, HR, legal, communications, design, etc.) in an effort to transform the organizational culture and improve outcomes for the public related to employment and fair labor practices.

This paper focuses on initial qualitative outcomes of the first Agile Corps pilot at the DOL. Quantitative measures of learning will be discussed but will not be the focus as we used a masterybased, competency-based learning approach ${ }^{17-25}$. Learnings that are transferable from the DOL WHD pilot will be applied to future, bigger pilots at other agencies, such as EPA and OFR, and, more broadly, to service-learning programs with students.

\section{Literature Review}

In part I of this paper, Agile Corps had not yet been designed. Even though we found no examples of PSL, we reviewed the literature for research-validated, modern educational methods and practices, as well as research on service learning. That literature review and subsequent research, synthesis, and ideation, led to the design of Agile Corps, the prototype ${ }^{11}$.

Before piloting, our literature review focused specifically on government service-learning programs (PSL). We found no such examples in the literature. However, the book Peak Academy chronicles the deployment of a Lean, continuous improvement educational program with workers in the city government of Denver, Colorado ${ }^{26}$. As opposed to an ongoing, multi-month service learning program, Peak Academy offers a few one-off courses. Each learner is eligible for two of the trainings: an introductory level training (Green Belt) and an advanced training (Black Belt or Superhero $)^{26-27}$.

- Green Belt Training: a 4-hour course on process improvement

- Green Belt for Leaders: a course on process improvement for supervisors through executive directors, designed to help learners support employee innovations initiatives and to build high-performing, innovative, data-driven teams

- Black Belt Training: a 5-day course on process improvement leadership; there are two versions for this, one for Denver city and county government employees and one for other government and nonprofit employees

- Public Service Superhero Training: a two-day virtual course in place of the Black Belt due to the global pandemic COVID-19, in an effort to reduce time away from government work during the crisis. 
The Peak Academy model diverges from the PSL model due to the separation between the classroom instruction and government public service work. In the Peak Academy model, the instructors ( 8 full-time staff) hope that the learnings continue and impact the government work of the learners, but there is no continued learning and coaching or post-service work reflection that continues to influence the government service work. However, the similarities and impact were significant enough to impact our work and to be cited as work upon which Agile Corps is built.

The similarities suggest the possibility of transferable insights or designs as we pilot Agile Corps at DOL. First, Peak Academy and Agile Corps are both government educational programs for adult civil servants. Both use lean principles with a focus on continuous improvement and the reduction of waste. Both intend to transform the culture, a definitive part of PSL programs. Both presume that such increases in efficiency and effectiveness through continuous improvement will result in cost savings to the government. By 2016, Peak Academy had trained over 5,000 workers and saved over $\$ 15$ million in government spending; by 2019 total savings had increased to over $\$ 37$ million with over $\$ 4$ million in 2019 alone $^{26-27}$.

The Agile Corps pilot builds on the Peak Academy model in three ways. First, Agile Corps more tightly integrates classroom training with government service work and reflection, constantly iterating between through the cycle and naturally embedding continuous improvement. This is a strong service learning approach. Second, Agile Corps not only infuses Lean Principles in the culture and work of government employees but it infuses Lean Startup methodologies which focuses on experimental testing launching new products and services ${ }^{28-34}$. Agile Corps goes beyond continuous improvement to include social entrepreneurship and social intrepreneurship. Third, Agile Corps tries to improve engineering through Human-centered Design (HCD) methodologies and Agile mindsets as well as apply engineering methodologies (like HCD and Agile) to other functions in the government ${ }^{35-39}$. This is an effort to improve government products and services for the public, or humanitarian engineering. Agile Corps uniquely combines humanitarian engineering and social entrepreneurship through service learning resulting in cultural transformation.

\section{Methodology}

The work to research, design, prototype, and pilot the Agile Corps program involved five research phases. First, we utilized an exploratory research and design process to create the concept. Next, we used an experimental research process to test and refine a prototype of Agile corps. Both phases were explained in Part I of this paper.

Here, in Part II, we describe three research or implementation phases. First, we performed research to customize the Agile Corps model for the needs of the DOL Wage and Hour Division (WHD) and learners. Second, we implemented the pilot at the DOL. Third, we immediately evaluated the initial impressions and impact of the program and learning. Each of these three steps involved different methodologies. All three steps are still embedded within an overall question: What are the learning needs and skills gaps of public servants who work in technology in the government? How might we design a program that fits the needs of those students as well as the government agencies' need for more high-quality technologists at all levels including junior levels and mid-levels?

The most important factors in determining which research methodology to use are the research questions ${ }^{12}$. Because our research questions are open-ended, lack a specific hypothesis, 
International Journal for Service Learning in Engineering, Humanitarian Engineering and Social Entrepreneurship Vol. 16, No. 1, pp. 58-89, Spring 2021

ISSN $1555-9033$

and seek to uncover the mindsets, fears, and difficulties of public servants in government institutions, a qualitative research methodology is best.

However, the general answers to the questions across the federal government were used to create the initial Agile Corps design ${ }^{11}$. Since the answers were used to design an unvalidated, educational program intervention to improve government products and services for the public, we also need a design experiment or design-based research methodology for validation. Design-based research (DBR) is characterized by pragmatism, theory, iterations, integration, and contextualization ${ }^{41-42}$.

Because DBR often is initiated by the educational researchers as opposed to practitioners and may never be implemented in an actual learning environment, we employ a more narrow version of DBR called Design-based Implementation Research. Design-based Implementation Research (DBIR) has four guiding principles. These include jointly negotiated work, iterative and collaborative design processes, development of theories, and design for viability ${ }^{43-49}$. Following those principles, this work was initiated and requested by different government agencies, $18 \mathrm{~F}$, and technologists who find it difficult to be hired by the government. Our design team includes government workers as well as the potential students. Theories guide and emerge from our design research and work. Finally, our goal is sustainability via career development and growth potential for junior and mid-level technologists brought into government service.

Design-based Research, in general, does not have to use a mixed methodology, though sometimes it does. In this case, we combined DBIR with an exploratory qualitative methodology (Part I); therefore we chose the mixed methodology called Human-centered design (HCD, usercentered design, or design thinking) as our overarching framework because it combines a qualitative methodology with $\mathrm{DBIR}^{50-53}$. In education, HCD is often called student-centered design or learner-centered design (LCD). Human-centered design is only a methodology, not a solution. It can be used to design a building, a project, software, a process, a service, a product, an environment, a program, an organization, or even a curriculum. Human-centered design mixes skills from engineering design such as defining the problem, setting the constraints, and rapid prototyping, with practices from the social sciences such as ethnographic studies, interviews, extracting insights from qualitative data, and empathic immersion ${ }^{54-57}$. In short, HCD keeps the design work centered on the users, the beneficiaries, or the community. In this work, HCD creates two pillars. First, instead of the traditional model where the designers go away, design a solution, and then bring it back to the community, in HCD, we practice participatory co-design where the community is involved in every stage of the design process ${ }^{58-60}$. Second, instead of the design team only including members from outside the community, the design team also includes federal government workers who lack the ability to hire the talent.

In this work, the design team includes a core team of four government workers and a larger team of 20 government workers. Second, we involved not only local design team members but also technologists outside of government.

Human-centered design is normally broken into three stages, Discover, Design, and Deliver. The first stage (Discover) is a research stage where you listen and learn from the community for whom and with whom you are designing, developing empathy and connecting yourself to the needs and desires of that community. The second stage (Design) is a stage of data analysis and synthesis of the previous qualitative and quantitative work, followed by ideation, prototyping, feedback, refinement, and iteration. The Discover and Design stages were completed in Part I of this paper ${ }^{11}$. The final stage (Deliver) is the stage of pilot planning, developing a feedback loop, defining 
success, partnerships, and developing business models for financial viability and sustainability. This paper, Part II, focuses on the Deliver stage (Table I).

TABLE I

Agile Corps Pilot

\begin{tabular}{|c|c|c|}
\hline \multicolumn{3}{|c|}{ HCD DELIVER STAGE } \\
\hline Phase & Research Questions & Methodology \\
\hline $\begin{array}{l}\text { Customization } \\
\text { Design Research for } \\
\text { Agile Corps Pilot }\end{array}$ & $\begin{array}{l}\text { - How many months should the program last? } \\
\text { daily, weekly, and monthly time for } \\
\text { instruction? } \\
\text { - What class length and frequency work best } \\
\text { with student schedules? } \\
\text { - What mode of instruction is preferred? } \\
\text { - What Agile corps tracks are most needed? } \\
\text { addressed to improve public outcomes of } \\
\text { student government service? }\end{array}$ & $\begin{array}{l}\text { Qualitative research - } \\
\text { interviews, observations, } \\
\text { focus groups }\end{array}$ \\
\hline $\begin{array}{l}\text { Conducting Agile } \\
\text { Corps Pilot }\end{array}$ & $\begin{array}{l}\text { - What is the definition of success? } \\
\text { - What is our monitoring \& evaluation plan? } \\
\text { - What is our feedback cadence? } \\
\text { What is the staffing plan? }\end{array}$ & $\begin{array}{l}\text { Agile philosophy, Scrum } \\
\text { and Kanban methodology }\end{array}$ \\
\hline $\begin{array}{l}\text { Initial Evaluation of } \\
\text { Agile Corps Pilot }\end{array}$ & $\begin{array}{l}\text { - What was the student experience of the PSL } \\
\text { program? } \\
\text { - How did they like it or dislike it? } \\
\text { - What percentage of students completed all } \\
\text { objectives or competencies? }\end{array}$ & $\begin{array}{l}\text { Mixed methods - qualitative } \\
\text { and quantitative research }\end{array}$ \\
\hline
\end{tabular}

In the first phase of this work, we utilized an exploratory research and design process to customize the Agile Corps design for the DOL. The Agile Corps model was designed to allow flexibility for customization to the specific needs of the federal government agency who purchased the service. The general Agile Corps model had not been customized for the DOL WHD group. To answer questions about the DOL WHD learner needs, motivations, and availability, we chose a qualitative methodology which helped to determine the learning topics, frequency, time, duration, focus, tracks, synchronicity, and more. Specifically, we employed interviews, observations, and focus groups.

Second, we implemented and ran the pilot at the DOL. We needed to determine feedback cadence, success criteria, staffing, and evaluation. Rather than a research methodology, we chose two implementation methodologies used by Agile teams for developing software-Scrum and Kanban (Table I) ${ }^{61-65}$. This choice allowed us to model the type of continuous improvement the 
students were learning, as we shared our process for constructing the course. Secondly, we invited them into our course construction process (participatory design) as they participated in Kanban and Scrum ceremonies such as Agile retrospectives providing feedback to continuously iterate and improve the program while it was being constructed.

Third, we immediately evaluated the initial impressions and impact of the program and learning. Because we wanted to understand the percentage of students that achieve all competencies as well as the satisfaction and experience of the learners, we chose a mixed methods approach (Table I). We used quantitative research to evaluate the learning and qualitative research to evaluate the experience and satisfaction.

The remainder of the paper is broken into two sections. First we provide a brief overview of the procedures for the customization research and program implementation. Then we provide the results of the initial evaluation research. This work will inform the iterative process and bigger, future pilots at other agencies to be presented in future papers.

\section{Procedure}

\section{Agile Corps Pilot: DOL Customization Research}

In Part I of this paper, $18 \mathrm{~F}$ sold a three-month pilot of Agile Corps to the DOL WHD, starting with a discovery sprint in August, two months ahead of an October start of the pilot program. The Agile Corps prototype was already designed and tested, so the purpose of this discovery research process was to determine how to adapt the program prototype to the specific needs of the DOL WHD learners. The $18 \mathrm{~F}$ team also used the discovery sprint to help the DOL WHD leadership determine how many and which WHD employees should participate in the Agile Corps PSL program. Not knowing who would be participating presented a problem for the research team; learning designers need access to learners in order to uncover learning needs and skills gaps through observation, assessments, and interviews. However, at the time of discovery, the WHD leadership did not yet know who they would place in the program for a majority of the program openings. The few employees that WHD leadership already wanted in the program were future employees who would start working at the DOL in October and were currently inaccessible.

The second limitation of the customization research was stakeholder-driven design. The customized design of the DOL WHD Agile Corps pilot was not solely based on the analysis and synthesis of the customization research but subject to the approval of WHD leadership including two Assistant Administrators. The customized pilot design was influenced by this collaboration rather than being solely data-driven.

With only two weeks to conduct a customization research discovery sprint, the $18 \mathrm{~F}$ team used a fast ethnography methodology in order to recruit, interview, analyze and synthesize without fully coding complete transcriptions ${ }^{66-67}$. Next, the findings were presented to WHD leadership and in multiple meetings and consultations with leadership, an agreement was made for the pilot design and which DOL employees should participate. The pilot would diverge from the prototype, making program execution and instructional design harder: a larger group of participants for a shorter service-learning program with a mixed-discipline cohort (Table II). 


\section{TABLE II}

Agile Corps: Prototype vs Pilot

\begin{tabular}{|l|l|l|}
\hline \multicolumn{1}{|c|}{ Program Component } & \multicolumn{1}{|c|}{ Prototype } & \multicolumn{1}{c|}{ Pilot } \\
\hline Cohort size & 6-20 participants & 35 participants \\
\hline Duration & $3-6$ months & 10 weeks \\
\hline Tracks & $\begin{array}{l}\text { Software engineering, design, } \\
\text { security, product management, or } \\
\text { data science }\end{array}$ & $\begin{array}{l}\text { Single mixed-discipline track } \\
\text { focused on HCD, Agile, and Lean }\end{array}$ \\
\hline $\begin{array}{l}\text { Individual mentorship } \\
\text { provided }\end{array}$ & Yes & Yes \\
\hline Office Hours & Yes & Yes \\
\hline
\end{tabular}

Instead of 6-20 participants, there would be 35. Instead of 3-6 months, the PSL program would last 2.5 months or 10 weeks. Originally, the Agile Corps prototype embeds HCD, Agile, and Lean Startup learning into a single track like design or multiple, parallel tracks like design and data science. The DOL WHD pilot design, instead, would use a single, mixed-discipline track where the general learning was HCD, Agile, and Lean Startup. This change was due to the WHD leadership's desire to apply these principles and methodologies outside of the narrowly defined group of technologists, and include employees that work on technical products and services. The pilot participants would include digital acquisition specialists, digital program managers, project managers, finance, etc. in addition to engineers, product managers, and designers. Training a larger, more heterogeneous group of learners for less time was going to be more difficult than the original prototype design. The $18 \mathrm{~F}$ team decided to continue with the pilot because it was still a chance to test some version of the prototype. Also, the process of adapting the prototype to the DOL WHD constraints could demonstrate to the participants the type of Agile mindset the students would be encouraged to develop.

The pilot matched the prototype in two ways. The pilot would include mentorship and office hours as planned. Mentors would be provided from 18F's staff of product managers, designers, data scientists, acquisition specialists, and strategists. Based on the customization research and WHD leadership agreement, the pilot design included five hours of weekly instructions, split between Tuesday and Thursday mornings with one hour of mentorship on Mondays and two hours of optional office hours on Friday (Figure I). 


\section{Program Overview - After Week 1, Until 12/15}

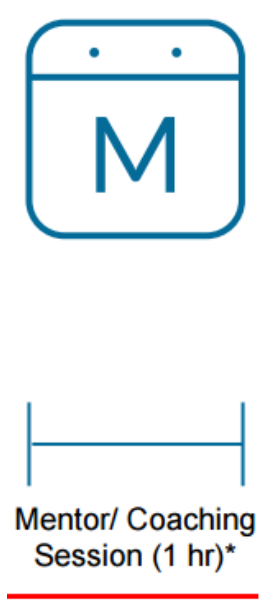

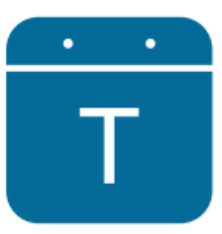
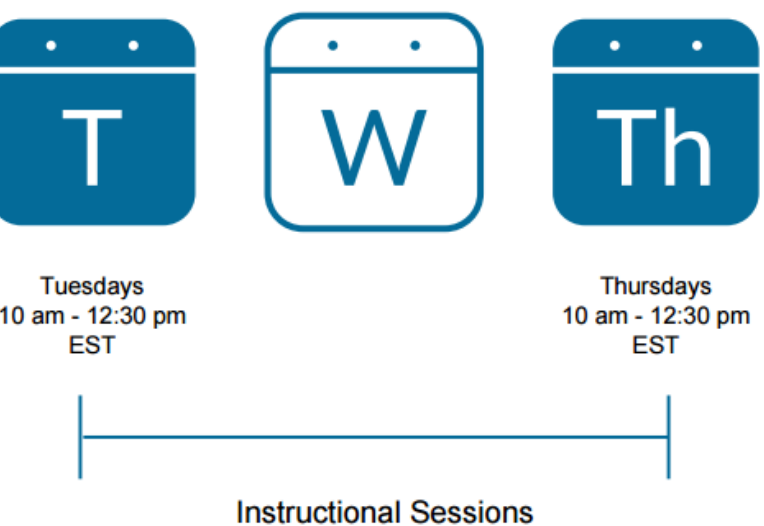

(5 hrs)
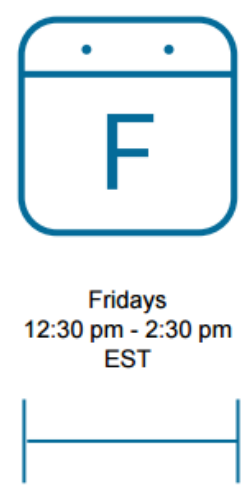

Office Hours

(2 hrs)

FIGURE I

Agile Corps Pilot Schedule

Lastly, the Agile Corps prototype could be synchronous or asynchronous. Since the DOL WHD employees participating in the Agile Corps PSL were in different cities, the $18 \mathrm{~F}$ team chose a semi-synchronous design including asynchronous learning online and project-based assignments as well as synchronous learning for live classroom sessions. Participants in the same city would gather together in person and connect via video to those in other cities while the instructors taught from Washington, DC, which was the city in which $60 \%$ of participants lived.

The $18 \mathrm{~F}$ team designed a two-day, in-person program overview and introduction to HCD, Lean Startup, and Agile to occur during week 1. The regular schedule then started in week 2 after those working outside of Washington, DC, had traveled back home (Figure I). Each week, participants would receive recap emails to help those who missed sessions and to aid students in explaining to their managers what they were learning. Weekly retrospectives would be held with the participants so that they could practice the Agile principle of team reflection and watch, in realtime, how the $18 \mathrm{~F}$ team changed the class based on the retrospective synthesis. Finally, each student would work on a public service, group project with other students. Students were asked to make the project part of their public service job.

\section{Agile Corps Pilot: DOL Implementation}

The $18 \mathrm{~F}$ team emailed the selected participants who were chosen by the DOL WHD leadership. Unfortunately, most of them had not signed up or volunteered for the program so they did not enter the program excited. The program kicked off with a soft launch in late October while the participants were still located in different offices around the country. Then in November, the 18F team conducted the official kick-off with all participants in-person in Washington, DC. This event provided a general overview of HCD, Lean Startup, and Agile.

Progress through the topics was tracked through a publicly accessible Trello board. As planned, recap emails and retrospectives occurred weekly, and the $18 \mathrm{~F}$ team adjusted the delivery 
mode and content as they learned what worked for the learners and what program or class components did not work well. In December, the $18 \mathrm{~F}$ team conducted a one-day training for WHD leadership to explain what the participants were learning and create a shared vision and increased buy-in so that employees had more flexibility to try innovative methods on their public service projects. Through the program implementation, the $18 \mathrm{~F}$ team faced four challenges.

First, the program started in October and November and crossed the winter holidays including Thanksgiving and Christmas. In the USA federal government, many federal workers have "use-itor-lose-it leave." If they do not use it, they will lose it. So, the use of vacation or leave is much higher in the months of November and December than the rest of the year. This meant people missed class or were busy trying to make up for job-related work to either prepare for leave or to catch up after returning from leave. To minimize this, the $18 \mathrm{~F}$ team canceled and postponed some live instruction weeks to accommodate the smaller attendance that would have resulted.

Second, many students had difficulty using the technological tools. The Department of Labor blocked access to Google Hangouts and Zoom, which were the videomeeting tools $18 \mathrm{~F}$ used in $18 \mathrm{~F}$ daily work. It was difficult for students to join not only live class sessions but also mentor meetings and office hours. As a temporary fix, participants outside of Washington, DC were asked to join on a personal device or without signing into the DOL virtual private network (VPN). Participants were also asked to call in through a phone, but that meant they could not see anything. As a medium-term solution, the $18 \mathrm{~F}$ team ran training sessions for participants. In the end, the $18 \mathrm{~F}$ team thought it would be better to use the DOL videoconference tool which was Adobe Connect. The $18 \mathrm{~F}$ team had avoided this as Connect is meeting software not educational software. Through research and working with the $\mathrm{CIO}$ office, the $18 \mathrm{~F}$ team discovered that the DOL had a license for the educational version of Adobe Connect, Adobe Learn. Once this was uncovered, the program switched to this option in November and ran training sessions for the students.

Third, the pilot design included public service-based, group projects for each student. These projects were supposed to be a natural part of their public service work and completed as group projects with other students who also had the same project as part of their public service work or job. Based on the WHD leadership's assignment of participants, there were participants who entered the program without any type of project. Others entered the program with a project but none of their teammates were assigned to the Agile Corps PSL so they were not all being trained. Others had a project and teammates who were also in Agile Corps to work on the project while being trained together. Due to the variety of project statuses, participants' experiences of the project-based learning were very diverse. Without shared projects and prioritization of projects by managers, students could not effectively work across cohorts. The $18 \mathrm{~F}$ team assigned people to groups as a temporary fix, but it meant there were participants working on a public service project not directly related to their public service work in their job.

Fourth, the process of recruiting, assigning, and assisting mentors was slower than expected. The ideal design had mentors ready on day 1, but student assignment did not happen until October. The $18 \mathrm{~F}$ team shared a survey with students on day 1 , the last week of October. The survey asked people to describe their job and the skills they were looking to acquire. In November, the $18 \mathrm{~F}$ team had made initial matches between mentors and mentees. Realizing the need for additional mentors, the $18 \mathrm{~F}$ instructional designers hosted an "Ask Me Anything" (AMA) event inside 18F to recruit more mentors. All mentors received a baseline level of training and were asked to introduce themselves via email. Mentors provided mentorship from mid-November through mid-January. In late December, $18 \mathrm{~F}$ mentors gathered for a retrospective to identify problems, suggest solutions, 
International Journal for Service Learning in Engineering, Humanitarian Engineering and Social Entrepreneurship Vol. 16, No. 1, pp. 58-89, Spring 2021

ISSN 1555-9033

and think through future mentorship opportunities. Due to different calendar/email software at the DOL and $18 \mathrm{~F}$, mentors and mentees could not share calendars which made scheduling mentorship meetings very slow.

Lastly, the 18F team created a list of HCD mindsets and Agile values students should embody by the end of the course. The team also created a list of Lean Startup and Agile principles in which students should demonstrate minimum competency through their project work (Table III).

TABLE III

Mindsets And Principles

\begin{tabular}{|c|c|c|c|}
\hline $\begin{array}{l}\text { Lean Startup } \\
\text { Principles }\end{array}$ & $\begin{array}{l}\text { HCD } \\
\text { Mindsets }\end{array}$ & Agile Values & Agile Principles \\
\hline \multirow[t]{4}{*}{$\begin{array}{l}\text { Experimentation } \\
\text { instead of } \\
\text { elaborate } \\
\text { planning }\end{array}$} & \multirow[t]{2}{*}{$\begin{array}{l}\text { Learn from } \\
\text { failure }\end{array}$} & \multirow[t]{2}{*}{$\begin{array}{l}\text { Value 2: Working } \\
\text { software over } \\
\text { comprehensive } \\
\text { documentation }\end{array}$} & $\begin{array}{l}\text { Principle 1: Our highest priority is to satisfy the } \\
\text { customer } \\
\text { through early and continuous delivery } \\
\text { of valuable software. }\end{array}$ \\
\hline & & & $\begin{array}{l}\text { Principle 7: Working software is the primary } \\
\text { measure of progress. }\end{array}$ \\
\hline & \multirow[t]{2}{*}{$\begin{array}{l}\text { Make it } \\
\text { (visual) }\end{array}$} & \multirow{2}{*}{$\begin{array}{l}\text { Value 2: Working } \\
\text { software over } \\
\text { comprehensive } \\
\text { documentation }\end{array}$} & $\begin{array}{l}\text { Principle 1: Our highest priority is to satisfy the } \\
\text { customer through early and continuous delivery } \\
\text { of valuable software. }\end{array}$ \\
\hline & & & $\begin{array}{l}\text { Principle 7: Working software is the primary } \\
\text { measure of progress. }\end{array}$ \\
\hline & \multirow[t]{3}{*}{$\begin{array}{l}\text { Creative } \\
\text { confidence }\end{array}$} & & $\begin{array}{l}\text { Principle 2: Welcome changing requirements, } \\
\text { even late in development. Agile processes } \\
\text { harness change for the customer's competitive } \\
\text { advantage. }\end{array}$ \\
\hline & & & $\begin{array}{l}\text { Principle 5: Build projects around motivated } \\
\text { individuals. Give them the environment and } \\
\text { support they need, and trust them to get the job } \\
\text { done. }\end{array}$ \\
\hline & & & $\begin{array}{l}\text { Principle 9: Continuous attention to technical } \\
\text { excellence and good design enhances agility. }\end{array}$ \\
\hline \multirow[t]{2}{*}{$\begin{array}{l}\text { Customer } \\
\text { feedback instead } \\
\text { of intuition }\end{array}$} & \multirow[t]{2}{*}{ Empathy } & $\begin{array}{l}\text { Value 3: } \\
\text { Customer } \\
\text { collaboration } \\
\text { over contract } \\
\text { negotiation }\end{array}$ & $\begin{array}{l}\text { Principle 1: Our highest priority is to satisfy the } \\
\text { customer through early and continuous delivery } \\
\text { of valuable software. }\end{array}$ \\
\hline & & $\begin{array}{l}\text { Value 1: } \\
\text { Individuals and } \\
\text { interactions over } \\
\text { processes and } \\
\text { tools }\end{array}$ & $\begin{array}{l}\text { Principle 2: Welcome changing requirements, } \\
\text { even late in development. Agile processes } \\
\text { harness change for the customer's competitive } \\
\text { advantage. }\end{array}$ \\
\hline
\end{tabular}


International Journal for Service Learning in Engineering,

Humanitarian Engineering and Social Entrepreneurship

Vol. 16, No. 1, pp. 58-89, Spring 2021

ISSN 1555-9033

\begin{tabular}{|c|c|c|c|}
\hline $\begin{array}{l}\text { Lean Startup } \\
\text { Principles }\end{array}$ & $\begin{array}{c}\text { HCD } \\
\text { Mindsets }\end{array}$ & Agile Values & Agile Principles \\
\hline \multirow[t]{2}{*}{$\begin{array}{l}\text { Iterative design } \\
\text { instead of doing } \\
\text { big design up } \\
\text { front }\end{array}$} & \multirow[t]{2}{*}{$\begin{array}{l}\text { Embrace } \\
\text { ambiguity }\end{array}$} & \multirow[t]{2}{*}{$\begin{array}{l}\text { Value 4: } \\
\text { Responding to } \\
\text { change over } \\
\text { following a plan }\end{array}$} & $\begin{array}{l}\text { Principle 2: Welcome changing requirements, } \\
\text { even late in development. Agile processes } \\
\text { harness change for the customer's competitive } \\
\text { advantage. }\end{array}$ \\
\hline & & & $\begin{array}{l}\text { Principle 11: The best architectures, } \\
\text { requirements, and designs emerge from self- } \\
\text { organizing teams. }\end{array}$ \\
\hline \multirow{9}{*}{$\begin{array}{l}\text { Iterative design } \\
\text { instead of doing } \\
\text { big design up } \\
\text { front }\end{array}$} & \multirow[t]{3}{*}{$\begin{array}{l}\text { Iterate, } \\
\text { iterate, } \\
\text { iterate }\end{array}$} & \multirow{2}{*}{$\begin{array}{l}\text { Value } 2 \text { : } \\
\text { Working software } \\
\text { over } \\
\text { comprehensive } \\
\text { documentation }\end{array}$} & $\begin{array}{l}\text { Principle 1: Our highest priority is to satisfy the } \\
\text { customer through early and continuous delivery } \\
\text { of valuable software. }\end{array}$ \\
\hline & & & $\begin{array}{l}\text { Principle 3: Deliver working software } \\
\text { frequently, from a couple of weeks to a couple } \\
\text { of months, with a preference to the shorter } \\
\text { timescale. }\end{array}$ \\
\hline & & $\begin{array}{l}\text { Value 4: } \\
\text { Responding to } \\
\text { change over } \\
\text { following a plan }\end{array}$ & $\begin{array}{l}\text { Principle 2: Welcome changing requirements, } \\
\text { even late in development. Agile processes } \\
\text { harness change for the customer's competitive } \\
\text { advantage. }\end{array}$ \\
\hline & Optimism & & $\begin{array}{l}\text { Principle 2: Welcome changing requirements, } \\
\text { even late in development. Agile processes } \\
\text { harness change for the customer's competitive } \\
\text { advantage. }\end{array}$ \\
\hline & & & $\begin{array}{l}\text { Principle 4: Business people and developers } \\
\text { must work together daily throughout the project. }\end{array}$ \\
\hline & & & $\begin{array}{l}\text { Principle 6: The most efficient and effective } \\
\text { method of conveying information to and within } \\
\text { a development team is face-to-face } \\
\text { conversation. }\end{array}$ \\
\hline & & & $\begin{array}{l}\text { Principle 8: Agile processes promote sustainable } \\
\text { development. The sponsors, developers, and } \\
\text { users should be able to maintain a constant pace } \\
\text { indefinitely. }\end{array}$ \\
\hline & & & $\begin{array}{l}\text { Principle 10: Simplicity--the art of maximizing } \\
\text { the amount of work not done--is essential. }\end{array}$ \\
\hline & & & $\begin{array}{l}\text { Principle 12: At regular intervals, the team } \\
\text { reflects on how to become more effective, then } \\
\text { tunes and adjusts its behavior accordingly. }\end{array}$ \\
\hline
\end{tabular}




\section{RESUlts}

In the Kirkpatrick learning evaluation model, there are four levels of evaluation ${ }^{68-70}$.

- [1] Reaction or Satisfaction (Did they like it?) - What was the student experience of the training? How (dis)engaging, (ir)relevant, (un)enjoyable, or (un)favorable did they find the training?

- [2] Learning (Did they learn it?) - To what extent did students acquire the intended knowledge, skills, motivation, confidence, and commitment?

- [3] Behavior (Do they do it?) - To what extent are on-the-job behaviors changed due to the training? Do students consistently apply what they learned during the training?

- [4] Results (What is the impact?) - What is the effect on the organization? What organizational outcomes or key results occurred due to changed behavior of students?

Because this is a public service-learning program, ultimately the goal is to affect not just the organization, but the public. Thus, we add a fifth level according to the Kirkpatrick Plus model ${ }^{71}$.

- [1] Reaction or Satisfaction (Did they like it?)

- [2] Learning (Did they learn it?)

- [3] Behavior (Do they do it?)

- [4] Results (What is the effect?) - What organizational outcomes or key results occurred due to changed behavior of students?

- [5] Social impact (What is the public good?) - What is the social impact on the public? What social good is produced for citizens, refugees, immigrants, or the environment?

For the DOL WHD Agile Corps Pilot, Level 4 results include the following.

- Shorten the process of producing communications, policy, working software, usable content, etc.

- Improve the acquisition of software

- Improve product management abilities within WHD

- Remove roadblocks of burgeoning documentation, long contract negotiations, and tirelessly produced memo after memo before making decision

- Faster decisions made at the team level

Level 5 results relate to wage and salary violations and remunerations affecting the public. Ultimately, this Agile Corps will help the DOL WHD to better identify, find, notify, and hold in compliance employers who have violated the law by not paying workers their wages. Agile Corps should also help WHD better collect those back wages and deliver them to workers thereby recovering months of rent, child care, food, etc.

The Kirkpatrick Plus model still suffers from a large jump between levels 2 and 3. A skill learned in one context is actually a different ability than the same skill in a different context ${ }^{72-75}$. Someone who learns a skill in a classroom (level 2) may actually not have that skill in a work context which prevents their behavior from changing (level 3). Based on the contextualized understanding of learning from social learning theory, here, we create a modified version of the Kirkpatrick Plus evaluation levels which we call Social Kirkpatrick Plus levels of evaluation.

- [1] Reaction or Satisfaction (Did they like it?) 
- [2] Classroom Learning (Did they learn it in the classroom?) - To what extent did students acquire the intended knowledge, skills, motivation, confidence, and commitment and demonstrate that ability in the classroom context?

- [2.5] On-the-job Learning (Did they learn it on the job?) - To what extent did students acquire the intended knowledge and skills and demonstrate that ability on the job?

- [3] Behavior (Do they do it?) - Have students acquired the motivation, confidence, commitment, environment, and structural support to apply what they learned in the training? Are their behaviors consistently changed?

- [4] Results (What is the effect?)

- [5] Social impact (What is the public good?)

The Social Kirkpatrick Plus model has three benefits. It highlights the artificial nature of the traditional classroom context and encourages instructional designers to create a training environment as close as possible to the environment students will experience while working for the public in their jobs. As the classroom environment approaches the conditions of the work environment, it is more likely the acquired skills in the classroom will be transferable and that level 2.5 will be reached. Secondly, it reminds instructional designers that further on-the-job training is often needed after classroom training due to differences in the contextualized learning experience. Third, the model focuses Level 3 (Behavior) on environmental and structural inhibitors and enablers of behavior change and recognizes the effect of context on non-cognitive skills such as motivation, perseverance, relationship, confidence, commitment, etc. These are included in Level 3 because of the context shift from Level 2 which affects non-cognitive skills as well as cognitive skills (knowledge and abilities).

The Agile Corps pilot sits somewhere between classroom training and on-the-job training since it involves both. In this analysis using the Social Kirckpatrick Plus model, we consider the Agile Corps PSL program to be Level 1 and 2. We consider evaluation level 2.5, which measures student learning in the job context, to be an assessment of participant learning in the job context after the program has ended. In other words, did the students acquire the knowledge and skills and demonstrate it in the context of the job without the support of mentors, project coaches, office hours, and intermittent classroom training?

Because this evaluation was done immediately at the conclusion of the 10 weeks of the program, the only levels that are assessed and presented here are reaction and classroom learninglevels 1 and 2. However, because the hybrid Agile Corps model does involve assisted application to job tasks with coaches and mentors, level 2 will include measures of assisted demonstration of skills in job contexts. We will continue to follow and measure on-the-job learning, behavior change, organizational results, and social impact (levels 2.5 - 5) of the program in future work.

The initial Level 1 and 2 evaluation of the Agile Corps pilot was completed by an independent evaluator from $18 \mathrm{~F}$ who did not take part in the program, in order to reduce bias. The evaluator spent two weeks conducting evaluation research upon the conclusion of the program. The evaluator reviewed Agile Corps content, end-of-class surveys, and retrospectives, and interviewed 20 people including $18 \mathrm{~F}$ business development workers who sold Agile Corps to the DOL, program facilitators, mentors, students, and the DOL WHD leadership.

Level 1: Reaction \& Satisfaction 


\section{Emails \& Technology}

Agile Corps facilitators sent weekly recap emails to the cohort and made space for frequent retrospectives. Recap emails were generally well received. Two interviewees said they found the emails especially useful for catching up on classes they missed and for forwarding along to their colleagues who were not in the cohort but had questions about what they were learning. Recap emails followed a predictable pattern, including sections for summary, assignment deadlines, reflection questions, and additional resources.

There were students who had a different experience with technology. In an email, one participant said: “We can't install software on our laptop. [18F] didn't seem to put any forethought into our needs and assumed 'things would just work.' ... How are they going to teach us to put customers first when they didn't plan for our customer needs?" Another added "During the group exercises, the remote users spent almost all of their time fighting technology." The next day remote users asked facilitators to postpone all training until $18 \mathrm{~F}$ and the DOL devised a workable solution for remote participants.

In response, the $18 \mathrm{~F}$ team changed the synchronous learning to be remote for all participants. The fully-remote classroom created an equivalent experience for all learners no matter if they were located in DC or located in other locations. The fully-remote classroom also forced the $18 \mathrm{~F}$ facilitators and instructional designers to address technology issues for all students, not just a minority. The $18 \mathrm{~F}$ team also ran training sessions as many participants were not accustomed to live, remote educational experiences nor the Adobe technology being used.

There were still students who had not fully mastered the technology. One exit survey noted "I hated the fact that people never learned how to bind their calls to WebEx. Our technology challenges created a significant number of challenges that we still need to address."

\section{Transition to Service Projects}

The Agile Corps vision involved a smooth transition and interplay between project-agnostic classes to project-based service-learning. At least one participant didn't experience it smoothly due to misunderstanding 18F's role: "I thought we were going to get an agile PM to support our project, to help us move through a live project. I thought we were going to get a hands on PM to help push us through!" Another participant's exit survey response (to the question "What advice would you give to another student who is considering taking this course?") suggests that Agile Corps' optional mentorship and office hours opportunities were much more important to this transition than they might have otherwise seemed. "Mentoring, office hours and homework ... is how I really sorted through what I thought I knew versus what I did know. I learned more in those environments than I did in the classroom."

Another factor inhibiting the smooth transition to project-based learning was the nature and number of projects. One participant said, "When we first talked about it, my understanding was that we wanted to identify key [service] projects that could benefit from an agile experience ... I didn't think we'd have 30 people and 20 projects. I thought we'd have maybe... three projects? You know, with self-organized teams - or at least teams mandated by managers for the duration of the course."

There were participants who joined Agile Corps without a project (they were asked to find one), while other participants were the only people assigned to their project (which made concepts 
like standups unnecessary). There were participants already working on projects being run in an agile way, such as one team which was already working with TTS Acquisitions, a sibling organization to $18 \mathrm{~F}$ inside of GSA. In general, participants expressed difficulty working on service projects with other participants due to a lack of shared projects and work project prioritization by their managers.

Project prioritization was also a recurring theme across interviews and exit surveys. There were participants who felt as though they did not have the authority to apply the skills they were learning to any project due to their manager's expectations of their role. One participant said, "The $[18 \mathrm{~F}]$ team could have done a more in-depth briefing with leadership beforehand. [The team] conducted a [DOL WHD] leadership training in December, but could have done a more in-depth briefing before then. The [18F] team ended up being more reactive than proactive." Another exitsurvey response read: "Given the fact that managers have volunteered staff to participate is not bad in itself, but ... managers [should have also gone] the extra step of identifying the highest priority service projects with highest potential value for which the entire project team can participate in the Agile Corps."

\section{Course Instruction}

Lectures were consistently lauded as one of the program's best parts. In their own words, participants said:

"[The trainers] were very good, very knowledgeable."

"Duane was the teacher for the majority of classes I attended. He's so dynamic and engaging. He really connected well with everyone in the group and I'd be surprised if anyone gave you any negative feedback on his teaching style.

"The teaching style was great, though I kinda like the in-person teaching more. Like the first two days we were there we were all able to interact, and when we broke into groups Duane played music - we all picked a genre - and it kind of made it a better environment. It's different when everyone's on camera and people are entering and leaving and the mic comes and goes."

End of class surveys further corroborated these sentiments (Figure II). 


\section{The instructor explained concepts clearly}

15

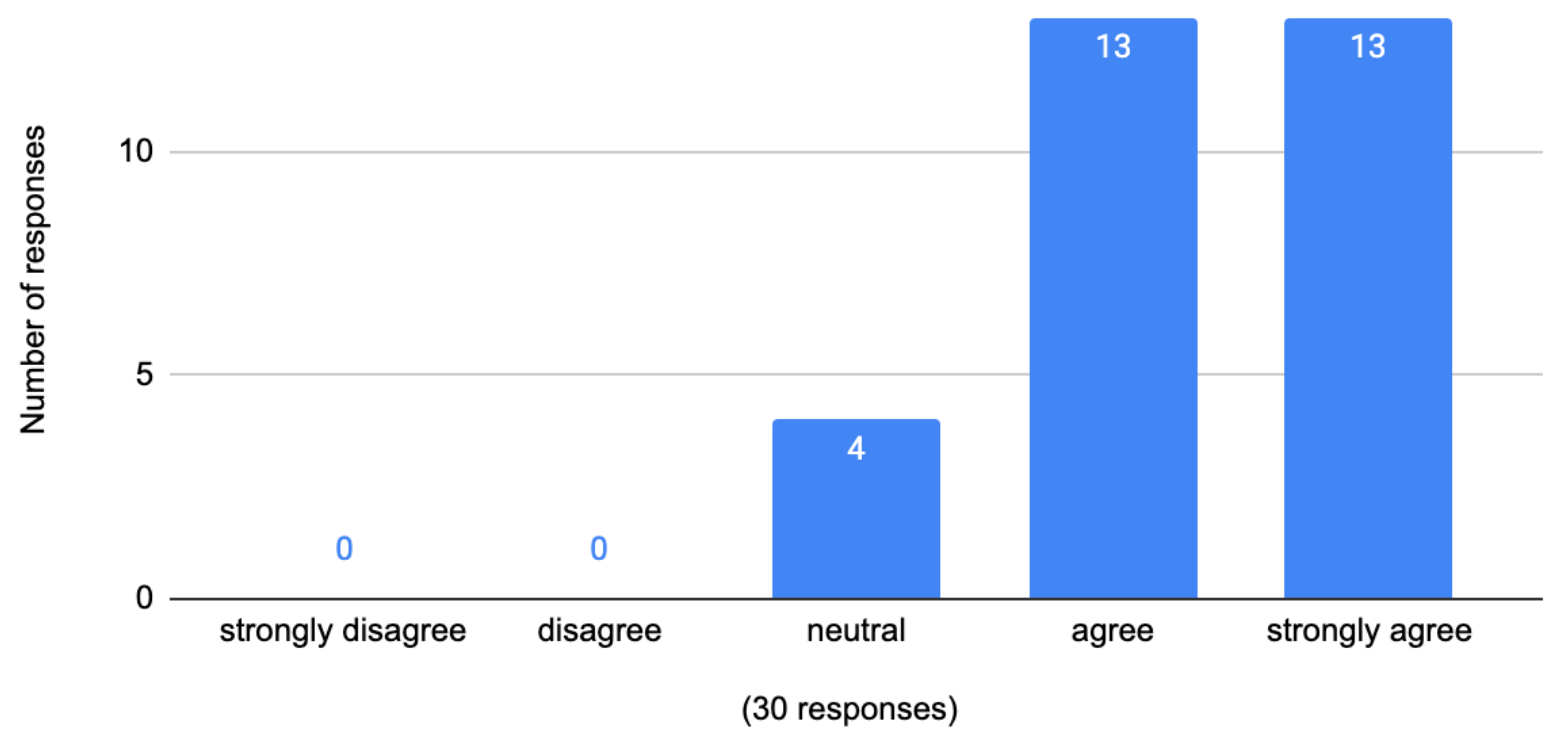

FIGURE II

Participant Ratings of Instructor Clarity

The success of Agile Corps classes seems also related to the facilitators' work in facilitating a conversational environment that lowered the boundary between teachers and students. In addition to the in-person kickoff meeting, weekly recaps, and retrospectives, the pair also instituted a "virtual-first workflow" (for example, assigning homework that shared concepts ahead of time) and used in-class polling to see how well lessons were received in real time. Many participants appreciated the degree to which these factors helped them learn.

\section{Pacing and Duration}

Some interviewees expressed frustration that Agile Corps continued throughout the month of December when they had planned vacations and/or absent teammates. December was also the time the pilot transitioned to more of a project-based learning environment - or, more accurately, to an environment in which participants began applying what they were learning to their existing public service projects. A few participants struggled with this. One said "I get the project-based decision but it got confusing to me to apply agile to my project, then human-centered design to my project, then to apply lean to my project." An exit survey question also highlighted this struggle. When asked what they might add to the program's courses, participants responded: "Not as much theory," "More real agile project exercises," "The application of methodologies," and "[To] see how some of the topics can be applied."

Some of the interviewed participants didn't really understand the ways in which Agile development, Human-centered Design, and Lean Startup overlap or support each other. They were frustrated to note how, in their opinion, graphics, explaining the relationships between the 
methodologies, appeared later in the pilot. Participants described classes as both "pre-packaged" and "in the weeds;" and responses to one exit-survey question reinforced this (Figure III).

\section{The course and subject matter were well organized}

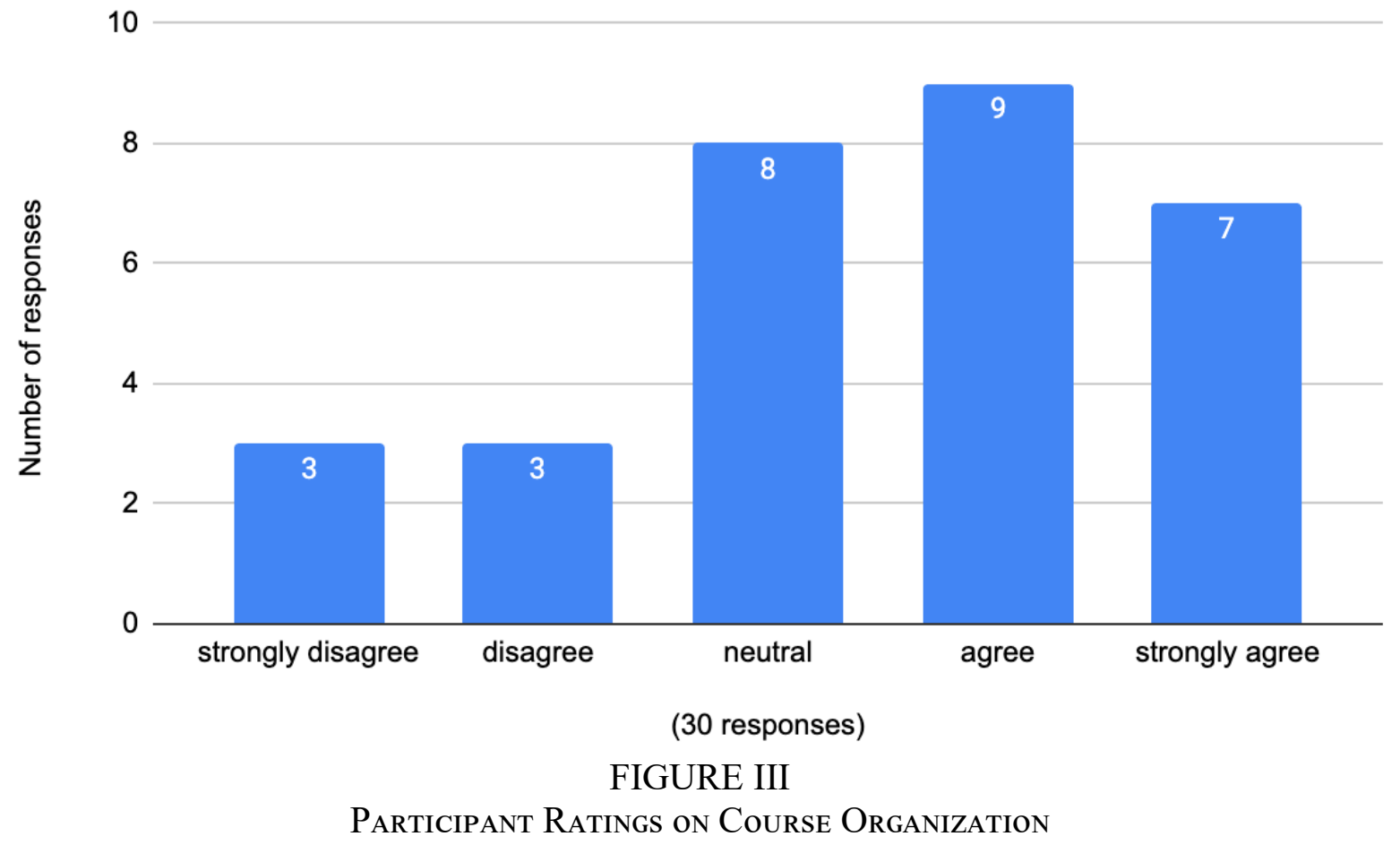

The last group of critical comments related to the duration of the program. Many participants asked for a shorter or more concentrated program in an attempt to facilitate continuity and cohesion:

"I think it should have been shorter. I don't know how long the course is slated to be. [Isn't] it a 40-hour course? If so, why not just do it in a week? It gets choppy when it's broken up. That'd be my constant feedback: do it in person. Knock it out instead of dragging it out."

"Everybody should devote - even if they're virtual - should carve out chunks of time. A week straight or two weeks. Maybe a week on/off to see if you can digest. I think that could carry more weight. It was otherwise really difficult to commit time. Office hours, mentorship, homework added to everything."

However, participant responses did not entirely trend in one direction. Some participants asked for a longer program, and someone actually suggested extending it to six months (the initial vision for the program). It is unclear whether the program and class length were too short or too long. 


\section{The length of individual classes (10:00 AM - 12:30 PM) was appropriate for the topics covered}

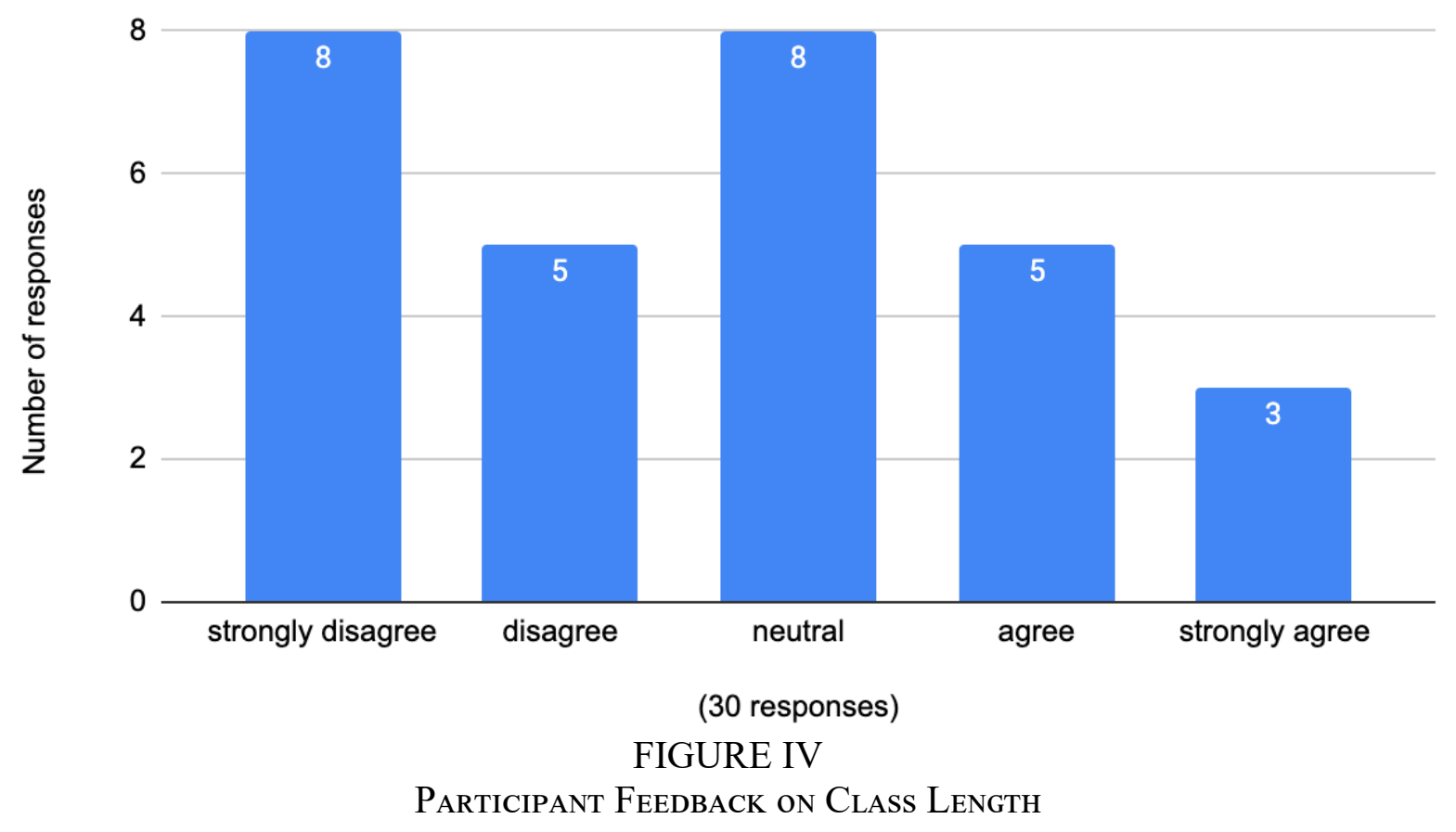

\section{Relevance}

The final recurring, instructional theme was the relevance of the material presented. Many participants expressed concern with the degree to which design thinking, Human-centered Design, Agile development, and Lean Startup could ever apply to government work. Other participants said it felt as though $18 \mathrm{~F}$ never really came to understand, empathize, or appreciate how the DOL WHD actually worked before Agile Corps. These participants felt as though $18 \mathrm{~F}$ just assumed WHD was not working as well as it can.

Other participants were concerned that many of the examples used in the program came from the private sector "world of software development," a world where requirements are sourced in a bottom-up fashion and solutions are iterative. (A majority of participants did enjoy thinking about their work iteratively.) Participants also expressed concern with the degree to which the program celebrated the private sector as a model for innovation. When discussing the Business Model and Mission Model Canvases, for example, some participants did not understand why the Business Model Canvas was presented first ${ }^{76-77}$.

\section{Service Projects}

Within the first month of the program, participants began to connect and apply their classroom learning to a specific service project ${ }^{78-83}$. All projects have a digital component that undergirds the public service work. 
- 14(c) Procedures Manual - A manual for Section 14(c) of the Fair Labor Standards Act which allows employers to receive permission from the DOL WHD to pay special subminimum wages to persons with disabilities

- Ag Safety Video - A safety video for agricultural workers

- Back Wage Working Group - Back wages are wages legally owed to workers who were unpaid or underpaid

- Customer Service Workgroup

- Davis-Bacon Survey Process - A process in which a survey is sent out to collect wage and fringe benefit information in order to make and publish fair wage determinations for labor in construction, repair, and alteration.

- Employee and Labor Relations Manual (ELM)

- Family Medical Leave Act (FMLA) - This grants 12 weeks of unpaid, job-protected leave without the need for supervisor approval

- Migrant and Seasonal Agricultural Worker Protection Act (MSPA) - This act protects migrant and seasonal agricultural workers by establishing wage protections, safety standards, disclosure requirements, and record keeping

- Training program

- WHISARD stabilization - a data processing and case management system for complaints and potential violations of labor laws and resulting investigations

Participants were asked to what degree did the classroom training affect their service projects.

"I worked on the FMLA resource tool, which is presently just a spreadsheet that links admins to regulations, laws, etc. So our group did a few things. The first thing [we did was to ask] the other group [to] review the spreadsheet for up-to-date violations, etc. Once that's complete ... we want to make it interactive.

And with the FMLA tool we're going to test our prototype. We're doing that in the next two weeks with volunteers: what works, what doesn't work, what they like/don't like."

Another participant described 14(c) work with a cross-functional team.

"My project was the Section 14(c) procedures manual. It's a document we're trying to put together to standardize the procedures required for 14(c) certification. I've worked with policy staff, someone from our IT department, as well as someone from enforcement.

We knew before Agile Corps started that our project was going to have several blockers associated with it. So we're still trying to work through those - and obviously there's a policy and a procedure component that requires more formal clearance. I think Agile Corps sort of helped us get that game plan together, kind of make a plan for maybe just starting small and embracing an iterative process. So we certainly have made progress and it certainly has made even starting this project a little less intimidating." 
One participant described the Ag safety video project, specifically how the team began to measure its own success more incrementally.

"I'm seeing [improvement] in our communications work - even internal comms. One of our guys in Agile Corps is creating a one-page storyboard of a video so he can get people's reaction much earlier. Previously he might write a script for the film, spend some production time, and then receive feedback later in the process. I think there's a lot of benefit to allowing teams and projects to work in this way."

One interviewee spoke to the program's impact more broadly.

"I am amazed when I look back and see how much we have accomplished in the last 3 months. The agile approach has revolutionized our project."

At the beginning of the program, there were participants responsible for multiple projects, while others had a single project or no projects. After assigning projects to all participants, there were multiple groups of work teammates from the same work project participating in Agile Corps together. In other cases, students participated in Agile Corps alone or as a representative for a larger team (in which case they were also actively engaged in the work of culture change).

The project selection and assignment process drew criticism from a participant. "Once they went down the path of 'what's your project,' they increased the [program's] scope dramatically. They also helped highlight something that WHD struggles with, [which is] prioritization. I would argue that my project is one of the highest priority projects - it's just not the sexiest. ... There were also a few wishlist projects that came up early on. People would say 'Oh I think [person 1] and [person 2] should work together because this is [a specific kind of project]!' And I was thinking 'No no no, this is wrong!" The participant felt the flashiest projects were chosen instead of the service projects of highest priority.

\section{Mentorship}

Satisfaction responses were solicited from participating mentors and mentees. This paper focuses on the satisfaction of the mentees, or student participants. Mentor-mentee relationships forged during the pilot fell into three categories. There were mentors and mentees who met regularly, those that met a few times, and those who never met. Some mentees felt exceptionally well matched with their mentor.

When the mentoring meetings were regular, mentees frequently commented how conversations with their mentor helped reinforce what they had heard in classes, build connections between theory and practice, and reduce anxieties about how cumbersome Agile, Human-centered Design, and Lean might be. One mentee said, "This is what [my mentor] really helped with: following every step isn't key, nor is having a worksheet. Empowerment is the goal. (That said, the clearance hurdles around our existing infrastructure are still too great.)"

In many ways, mentorship helped mentees see a direct path between what they were learning in the program and the avenues available for their own future growth as well as the growth of the organization. One mentor said, "We often discussed organizational-wide challenges to implementing the materials that were being taught." Another participant added "It's particularly 
challenging in government where we have other requirements we need to manage like records management requirements or the Paperwork Reduction Act. Human-centered Design is difficult to do with people external to the agency because of the sensitivities around information collection. I know we're not alone. 18F, OMB, and others have tried to streamline that process. But every team needs to work its way through that. That's where I see mentorship's greatest value."

Most mentees were project-oriented and did not see their mentorship as a tool for personal professional development. One mentee, "It would have been really helpful if each project had a mentor. [I wish I] had someone who could consult on my project vs. everyone having a mentor." This response is supported by participant responses to the exit survey question asking if mentorship was a helpful addition to in-class instruction. Reactions were mixed (Figure V).

\section{Mentorship was a helpful addition to the in-class instruction} 10

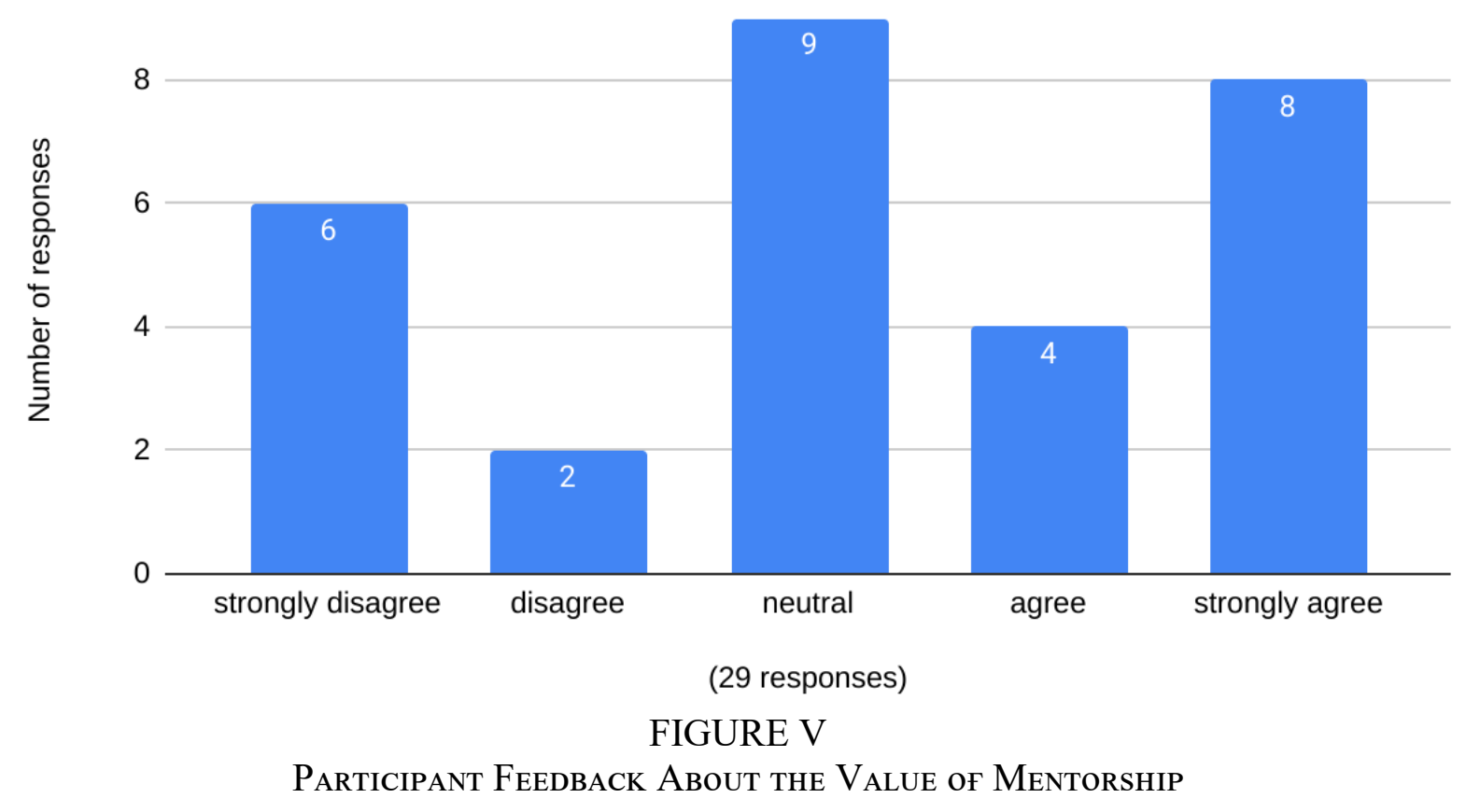

\section{Satisfaction with Student Outcomes}

Agile Corps participants described the program and its impact in altogether positive terms.

"Human centered design gives us two things. Not only does it allow us to get feedback earlier, it also helps us address our perception issues [with] field offices all across the country. Human-centered design has inspired us to go out to those offices, [which] increase[s] adoption and promote[s] empathy across the Department."

"I feel like a lot of these ideas and concepts really helped me think through problems in a way I previously didn't. I know for sure my communication and the ways I express and collect ideas has improved." 
International Journal for Service Learning in Engineering, Humanitarian Engineering and Social Entrepreneurship Vol. 16, No. 1, pp. 58-89, Spring 2021

ISSN 1555-9033

"Agile Corps changed my way of thinking. Before I would act on things a lot more quickly. Now I sit back and go through my steps: What should I do? Agile Corps helped me plan, set my goals, reach out to customers and ask what they want to get from it... I take my time and plan a lot better which makes it easier because then I can act on small goals."

"We knew before Agile Corps started that our project was going to have several blockers associated with it. So we're still trying to work through those - and obviously there's a policy and a procedure component that requires more formal clearance. I think Agile Corps sort of helped us get that game plan together, kind of make a plan for maybe just starting small and embracing an iterative process. So we certainly have made progress and it certainly has made even starting this project a little less intimidating."

"My takeaway is to use agile principles, research ahead of time, and keep users engaged early and often. Work iteratively; don't just wait until you have the MVP."

Most participants described Agile Corps as empowering. Participants said the program helped them see their impact in days and weeks rather than months. Many interviewees intimated a desire to more deliberately and uniformly collaborate on future service projects at WHD.

Participants also felt that Agile Corps helped them identify avenues for future growth. Many participants spoke about the benefits that could come from broader adoption of the principles and practices of Agile, Lean, and Human-centered Design. Specifically, they expressed a desire for WHD to think more critically about project prioritization, work-in-progress (WIP) limits, and perproject success metrics.

\section{Level 2: Learning}

A competency-based assessment model was used in which students needed to demonstrate a minimum level of competency in all the mindsets and principles through various activities and artifacts. In workshops and through service projects, $100 \%$ of participants demonstrated competency with the pilot's core concepts and principle methods, such as: starting with user needs, iterative development, usability testing, Kanban, project prioritization, and retrospectives. One hundred percent of participants demonstrated all principles and mindsets for Agile, Humancentered Design, and Lean found in Table III. Lastly, during interviews, $100 \%$ of participants were conversant with words and phrases often used by technologists, such as "discovery," "market fit," "usability testing," "MVP" (minimum viable product), "blockers," etc ${ }^{84}$.

\section{Recommendations And Future Work}

The next steps of the Agile Corps initiative follow two perspectives-the internal, organizational impact and external social impact for the DOL WHD as well as the external government-wide impact of the Agile Corps for 18F. At the DOL, the next steps are monitoring and evaluation of the impact of the pilot. Specifically, we want to measure contextual learning after the classroom sessions and mentorship has ended (Level 2.5), sustained behavior change in their public service jobs (Level 3), organizational impact (Level 4), and ultimately social impact on laborers, labor 
rights, and employers (Level 5). Secondly, across government, we want to continue to test which Agile Corps model works to resolve the lack of junior and mid-level technologists in government with career growth paths. This paper describes a $100 \%$ internal Agile Corps model in which all participants are already government workers; no one is hired into government through the program. The original Agile Corps model uses a mixed cohort of new recruits with government workers. The original model requires $18 \mathrm{~F}$ to use its faster hiring mechanism to hire people directly into 18F into government, and run Agile Corps while the longer government agency hiring process continues in the background, preparing to hire the $18 \mathrm{~F}$ recruits when the Agile Corps PSL ends. One possible pathway is for the $18 \mathrm{~F}$ Talent team to add training (Agile Corps) to its Recruitmentas-a-Service (RaaS) offering to other agencies; then $18 \mathrm{~F}$ would train people they recruit for other agencies. However, it is possible that the $100 \%$ internal version of Agile Corps, tested at the DOL, can still address the problem using normal government hiring timelines to grow the community of junior and mid-level technologists. Measuring the impact of this pilot will help determine the effect of the $100 \%$ internal model on the lack of junior and mid-level technologists.

Additionally, there are a number of recommendations that we can make for future, bigger pilots of the Agile Corps model at other agencies and in other divisions of the DOL. Some of the recommendations are for the government agency hosting the pilot; while others are for the $18 \mathrm{~F}$ facilitators. They are labeled.

- [AGENCY] Foster an internal learning culture - Continue meeting, reflecting, and sharing work on a weekly basis, build a documentation culture with a publishing platform, and improve onboarding.

- [AGENCY] Focus on fewer, more well-defined projects - Choose fewer service projects, projects where all team members are current or former members of Agile Corps. Define success for all projects.

- $[18 \mathrm{~F}]$ Identify collaboration platforms and plan for remote workflows early - Improve research on technology constraints in the Agile Corps customization discovery process at every agency and prioritize a "virtual-first" classroom design for the program.

- [AGENCY, 18F] Create space for participation in the PSL program - 18F should help agencies choose and better communicate required components of the program like mentorship and homework, and reduce workload to give time for students to participate.

- $[18 \mathrm{~F}]$ Reframe program and participation - Consider reframing participants as fellows or founding members of an innovation community and allowing participants to volunteer instead of being chosen by the agency.

- $[18 \mathrm{~F}]$ Create a website - A website facilitates learning and sharing the program across government.

- $[18 \mathrm{~F}]$ Cover less material with greater depth - Introduce the connections between Lean Startup, Agile, and HCD earlier and create deeper experiences in applying those approaches.

- $[18 \mathrm{~F}]$ Better incorporate mentors - Mentors should attend program launch and closing, attend classes, possibly lead some classes, and potentially help define learning objectives and class material.

- $[18 \mathrm{~F}]$ Incorporate evaluation during the program - Stronger feedback loops lead to realtime evaluation and redesign through the use of an evaluator or auditor who samples classes or project meetings and helps bring feedback to the facilitators and designers. 
In the introduction, we explained how the PSL model can be used in primary, secondary, and higher education as a "service-learning as pedagogical training" framework to transform the organizational culture of the education institution. Public Service-Learning can be used to improve the agility and design literacy of an organizational culture as in the example of Agile Corps. More interestingly, PSL can be used to train faculty in schools and universities to better implement service-learning with their students. In this case, service-learning becomes the means to teach how to implement service-learning, transforming the culture across an educational institution. The second implication, mentioned in the introduction, for schools and higher-education institutions is to lengthen the duration of service-learning programs beyond the length of a quarter, trimester, or semester course. A longer duration, as demonstrated in Agile Corps, allows more learning and impact.

The Agile Corps pilot evinces two other ways to apply PSL to schools and higher-education institutions. First, transform the service-learning approach from an approach about service goals and individual learning goals to an approach about service goals and communal, organizational or class learning goals. Traditionally, in schools and universities, the service-learning approach tries to balance the service goals with the individual learning goals by focusing on what service can be done and what learning can be achieved during the length of a particular service-learning course or class. In Agile Corps and in PSL, while individual learning is important, there is greater priority on the organizational or class learning, learning about what causes the most impact in the service work. For example, if a participant leaves the government, they are replaced by someone else to continue achieving the service goals and impact. If an individual switches to a different project in a different part of the government, they are replaced by someone else to continue pursuing the service goals. Thus, in PSL, the service-learning outlasts the individual learning because the service and, thereby, the service-learning is ongoing. This suggests that schools and universities might employ a model that uses on-going projects or partnerships with community organizations that outlast a particular student or student group or class session, and simply allow the changing of students at the start of each semester or trimester or quarter. In this PSL model, the documentation of class or organizational learning is key for new participants beginning the service work, highlighting the priority of the class or organizational learning over individual learning. Over time, as individual learners and participants change, the organization served by students or the class is improving its learning and understanding about how best to implement the service and how best to achieve and surpass social impact goals.

Second, the Social Kirkpatrick Plus evaluation model for PSL can be applied to servicelearning in schools and universities. It can be applied directly for PSL of school and university staff and in the "service as pedagogical training" framework for faculty. Also faculty can use the Social Kirkpatrick Plus evaluation model to evaluate the service-learning in their courses. The only change is the transformation of the phrase "on-the-job learning" in PSL to "in-the-field learning" in traditional service-learning. Ultimately the use of the Social Kirkpatrick Plus evaluation model for PSL implies that service-learning in school and universities needs to improve its ability to measure the true social impact of the service projects completed by students. Truly measuring social impact will equitably elevate the social impact goals to the learning goals.

\section{Conclusion}


International Journal for Service Learning in Engineering, Humanitarian Engineering and Social Entrepreneurship Vol. 16, No. 1, pp. 58-89, Spring 2021

ISSN 1555-9033

Public service-learning (PSL) is a learning approach and strategy that combines learning objectives, instruction, and reflection with, specifically, public or government service on behalf of the public. Agile Corps is a PSL program designed to address the problem of a lack of junior and mid-level technologists with career pathways in the federal government. This work documents and evaluates the first pilot of Agile Corps at the Department of Labor's Wage and Hour Division (DOL WHD).

The pilot reinforced the advantages PSL has over traditional service learning programs. First, because PSL participants are adult government workers, service projects do not need to be found; they are already inherently part of their work. Second, even though a PSL program is designed to focus on educational benefits of the learner (public servant), PSL naturally creates a balance between benefits to the public servant (learner) and benefits to the public community. We hope to measure the benefits to the community in continued, future work.

The pilot also highlighted the applicability of PSL to schools, colleges, and universities. First, PSL can be used for training of school or university staff or pedagogical training for faculty to achieve organizational culture change. The school or university culture change can be related to any change, or, more specifically, the change can be the catalyst of service-learning through most school and university courses. In this "service-learning as pedagogical training" framework, service-learning is the faculty training and means to increase student service-learning in the courses. Second, schools and universities can apply the PSL model to increase the duration of service-learning programs beyond the duration of courses. Third, schools and universities can move from balancing service goals with individual learning to balancing service goals with class or organizational learning. In this model, schools and universities can enter into long-term service partnerships with community organizations, switching and substituting students with the start of each new quarter, trimester, or semester. As students change, the documentation of organizational learning is important for incoming students, elevating the class or organizational learning over the individual learning. The organizational learning goal is to learn how to implement the service project or work (often of a partner organization) in such a way as to improve, surpass, or achieve intended impact more effectively or efficiently. Fourth, schools and universities can apply the Social Kirkpatrick Plus evaluation model in order to equitably elevate the social impact goals of the service with the student learning goals through the true measurement of social impact.

In this work, we presented the use of a human-centered design (HCD) methodology to guide the customization research, design, and implementation of the Agile Corps pilot at the DOL WHD in Washington, DC. Through the customization research, the pilot was designed to include two 1.5-hour class sessions each week, weekly office hours (two hours), and an hour of weekly mentoring. The pilot included a one-day training for executive leaders as well as service project assignments for participants. Recap emails were sent after each class, and retrospectives were held weekly. After experiencing technical difficulties, the facilitators switched to a fully online model to make the experience equivalent for DOL participants in Washington, DC and those in other locations in the US. The facilitators also worked to find service projects for participants who joined without one. Lastly the facilitators found mentors for each person and worked to facilitate mentoring relationship issues when any mentor was not meeting regularly with their mentee.

An independent auditor evaluated the pilot after its conclusion. Qualitative learner satisfaction results were presented. Overall, participants described a positive impact of the Agile Corps program which affected a large change in the perspectives of participants. Participants 
demonstrated competency with the pilot's core concepts and principle methods. Participants became conversant with words and phrases often used by technologists. Most participants described Agile Corps as empowering. All participants found the instructors and teaching to be good or excellent and were satisfied with outcomes. Participants had mixed feelings about project selection, project prioritization, the duration of class, the organization of topics, and the helpfulness of mentorship.

Quantitative learning achievement results were also presented. A competency-based, mastery-based model was utilized during this pilot. All participants demonstrated at least the minimum competency in all learning objectives, mindsets, and principles.

The next steps are to measure the behavior change, organizational impact, and external social impact of the PSL program at the DOL. To sustain behavior change after Agile Corps ends and ensure ultimate social impact upon labor rights and wage equity, the DOL WHD leadership asked $18 \mathrm{~F}$ what additional measures should be implemented. Nine suggestions were made.

- Have goal-setting workshops every six months for each project.

- Assign a Product Owner to each project and empower them.

- Set up a Kanban Board at the National Office.

- Have monthly demo days.

- Have monthly "Agile 101," "Lean Startup 101," and "HCD 101" sessions.

- Have Agile Corps participants meet together quarterly to reflect and brainstorm.

- For project teams, encourage daily standups and retrospectives.

- Focus on training teams to use the right collaboration tools.

- Encourage that all meetings be video chat by default.

Lastly, we will run larger Agile Corps pilots using the learnings from the DOL WHD pilot. We will continue to test the model and measure the impact of Agile Corps on the governmentwide problem of a lack of junior and mid-level technologists in the government with career pathways.

\section{ACKnowledgment}

The authors would like to thank the design \& facilitation team of Duane, Cat, and Jessie; the evaluator Andrew, the project advisors Sarah and Sasha; the project sponsor Hillary; the first client - Anne and Rachel at the Department of Labor Wage and Hour Division; as well as all of the learners, mentors, nonprofits, and agency management who participated in the interviews, observations, prototype feedback sessions, and pilot implementation. 
International Journal for Service Learning in Engineering,

Humanitarian Engineering and Social Entrepreneurship

Vol. 16, No. 1, pp. 58-89, Spring 2021

ISSN 1555-9033

\section{REFERENCES}

1 Dyck, Haley Van. "How a start-up in the White House is changing business as usual." Haley Van Dyck: How a start-up in the White House is changing business as usual | TED Talk | TED.com. 2016. Accessed May 23, 2017.

https://www.ted.com/talks/haley van dyck how a start up in the white house is changing business as us ual.

2 Marnewick, Carl. "Benefits of information system projects: The tale of two countries." International Journal of Project Management 34, no. 4 (2016): 748-760.

3 OMB. Innovative Contracting Case Studies. Washington, DC: OMB, 2014. Accessed November 29, 2017. https://obamawhitehouse.archives.gov/sites/default/files/microsites/ostp/innovative_contracting_case_studies_2 014 - august.pdf.

4 NCMA. Annual Review of Government Contracting. Washington, DC: NCMA, 2016. Accessed December 1, 2017. https://www.ncmahq.org/docs/default-source/default-document-library/pdfs/exec15---ncma-annualreview-of-government-contracting-2015-edition.

$5 \quad$ Peck, Louis. "America’s \$320 Billion Shadow Government." The Fiscal Times, September 28, 2011. Accessed December 1, 2017. http://www.thefiscaltimes.com/Articles/2011/09/28/Americas-320-Billion-ShadowGovernment.

6 Rein, Lisa. "OPM seeks to 'untie the knots' in federal hiring process." Washington Post, March 9, 2015. Accessed December 1, 2017. https://www.washingtonpost.com/politics/opm-seeks-to-untie-the-knots-infederal-hiring-process/2015/03/09/f70c4c50-c68f-11e4-a1996cb5e63819d2 story.html?utm term=.f18d00232778.

7 Monroe, John S. "8 reasons why the government hiring process doesn’t work." FCW, September 11, 2009. https://fcw.com/articles/2009/09/11/fcw-insider-8-reasons-government-hiring-broken.aspx.

8 Eggers, William D. Delivering on Digital: The Innovators and Technologies that are Transforming Government. RosettaBooks, 2016.

9 Clarke, Amanda. "Digital Government Units: Origins, Orthodoxy and Critical Considerations for Public Management Theory and Practice." (2017).

10 Kamensky, John M. Creating IT Start-Ups In Government. Washington, DC: IBM Center for the Business of Government, 2017. Accessed November 29, 2017. http://www.businessofgovernment.org/blog/businessgovernment/creating-it-start-ups-government.

11 Udoewa, Victor. "Agile Corps-A Public Service-Learning Program Part I." International Journal for Service Learning in Engineering, Humanitarian Engineering and Social Entrepreneurship 13, no. 2 (2018): 93-119.

12 Ehrlich, Thomas, and Barbara Jacoby. "Service-learning in higher education: Concepts and practices." San Francisco, CA: Jossey Bas (1996).

13 Cohen, Michael D., Daniel A. Levinthal, and Massimo Warglien. "Collective performance: modeling the interaction of habit-based actions." Industrial and Corporate Change 23, no. 2 (2014): 329-360.

14 Knudsen, Thorbjørn. "Organizational routines in evolutionary theory." Handbook of organizational routines 125 (2008): 151.

15 Driskill, Gerald WC. Organizational culture in action: A cultural analysis workbook. Routledge, 2018.

16 Winter, Sidney G. "Habit, deliberation, and action: Strengthening the microfoundations of routines and capabilities." Academy of Management Perspectives 27, no. 2 (2013): 120-137.

17 Anderson, L., and I. H. Block. Mastery learning in classroom instruction. New York: Macmillan, 1975.

18 Armacost, Robert L., and Julia Pet-Armacost. "Using mastery-based grading to facilitate learning." In 33rd Annual Frontiers in Education, 2003. FIE 2003., vol. 1, pp. T3A-20. IEEE, 2003.

19 Jazayeri, Mehdi. "Combining mastery learning with project-based learning in a first programming course: an experience report." In 2015 IEEE/ACM 37th IEEE International Conference on Software Engineering, vol. 2, pp. 315-318. IEEE, 2015.

20 Voorhees, Richard A. "Competency-Based learning models: A necessary future." New directions for institutional research 2001, no. 110 (2001): 5-13.

21 Gonczi, Andrew. "12 Competency-based learning." Understanding learning at work (1999): 180.

22 Dubois, David D. Competency-based performance improvement: A strategy for organizational change. HRD Press, Inc., 22 Amherst Road, Amherst, MA 01002, 1993. 
International Journal for Service Learning in Engineering, Humanitarian Engineering and Social Entrepreneurship Vol. 16, No. 1, pp. 58-89, Spring 2021

ISSN 1555-9033

23 Voorhees, Alice Bedard. "Creating and implementing competency-based learning models." New directions for institutional Research 2001, no. 110 (2001): 83-95.

24 Henri, Maria, Michael D. Johnson, and Bimal Nepal. "A review of competency-based learning: Tools, assessments, and recommendations." Journal of engineering education 106, no. 4 (2017): 607-638.

25 Chyung, Seung Youn, Donald Stepich, and David Cox. "Building a competency-based curriculum architecture to educate 21st-century business practitioners." Journal of Education for Business 81, no. 6 (2006): 307-314.

26 Elms, Brian., Wogan, J. B.. Peak Performance: How Denver's Peak Academy Is Saving Millions of Dollars, Boosting Morale and Just Maybe Changing the World. and How You Can Too!. United States: e.Republic, 2016.

27 Peak Academy Training. City and County of Denver Official Site, 2020. https://www.denvergov.org/content/denvergov/en/mayors-office/programs-initiatives/peak-performance/peakacademy/training.html.

28 Kilpatrick, Jerry. "Lean principles." Utah Manufacturing Extension Partnership 68, no. 1 (2003): 1-5.

29 Staats, Bradley R., David James Brunner, and David M. Upton. "Lean principles, learning, and knowledge work: Evidence from a software services provider." Journal of operations management 29, no. 5 (2011): 376390.

30 Gothelf, Jeff. Lean UX: Applying lean principles to improve user experience. " O'Reilly Media, Inc.", 2013.

31 Ries, Eric. The lean startup: How today's entrepreneurs use continuous innovation to create radically successful businesses. Currency, 2011.

32 Reis, Eric. "The lean startup." New York: Crown Business (2011): 27.

33 Eisenmann, Thomas R., Eric Ries, and Sarah Dillard. "Hypothesis-driven entrepreneurship: The lean startup." Harvard Business School Entrepreneurial Management Case 812-095 (2012).

34 Ghezzi, Antonio, and Angelo Cavallo. "Agile business model innovation in digital entrepreneurship: Lean startup approaches." Journal of business research 110 (2020): 519-537.

35 Boy, Guy A., ed. The handbook of human-machine interaction: a human-centered design approach. CRC Press, 2017.

36 Cooley, Mike. "Human-centered design." Information design (2000): 59-81.

37 Cockburn, Alistair. Agile software development: the cooperative game. Pearson Education, 2006.

38 Beck, Kent, Mike Beedle, Arie Van Bennekum, Alistair Cockburn, Ward Cunningham, Martin Fowler, James Grenning et al. "Manifesto for agile software development." (2001): 2006.

39 Dingsøyr, Torgeir, Sridhar Nerur, VenuGopal Balijepally, and Nils Brede Moe. "A decade of agile methodologies: Towards explaining agile software development." (2012): 1213-1221.

40 Bryman, Alan. Social research methods. Oxford university press, 2016.

41 "Explanation - What Is Design-Based Research (DBR)?" Explanation - What Is Design-Based Research (DBR)? 2006. Accessed April 11, 2016. http://dbr.coe.uga.edu/explain01.htm.

42 "Design-Based Research: An Emerging Paradigm for Educational Inquiry." Educational Researcher 32, no. 1 (2003): 5-8. Accessed April 11, 2016. doi:10.3102/0013189x032001005.

43 Tatar, Deborah. "The design tensions framework." Human-Computer Interaction 22, no. 4 (2007): 413-451.

44 Penuel, William R. "Infrastructuring As a Practice for Promoting Transformation and Equity in Design-Based Implementation Research." (2015).

45 Penuel, William R., and Angela Haydel DeBarger. "A Research-Practice Partnership to Improve Formative Assessment in Science."

46 Roschelle, Jeremy, Jennifer Knudsen, and Stephen Hegedus. "From new technological infrastructures to curricular activity systems: Advanced designs for teaching and learning." In Designs for learning environments of the future, pp. 233-262. Springer US, 2010.

47 Coburn, Cynthia E., Jennifer L. Russell, Julia Heath Kaufman, and Mary Kay Stein. "Supporting sustainability: Teachers' advice networks and ambitious instructional reform." American Journal of Education 119, no. 1 (2012): 137-182.

48 Sabelli, Nora, and Chris Dede. "Empowering Design-Based Implementation Research: The Need for Infrastructure."

49 "Design Based Implementation Research." DBIR $\rightarrow$..) Principles. 2016. Accessed April 11, 2016. http://learndbir.org/principles. 
International Journal for Service Learning in Engineering, Humanitarian Engineering and Social Entrepreneurship Vol. 16, No. 1, pp. 58-89, Spring 2021

ISSN $1555-9033$ Cambridge: MIT Press, 2000.

51 IDEO.org. HCD Toolkit. San Francisco: IDEO.org, 2013. 2nd edition.

52 IDEO.org. The Field Guide to Human-centered Design. San Francisco: IDEO.org, 2015. 1st edition.

53 Friedman, Batya, and David Hendry. "The envisioning cards: a toolkit for catalyzing humanistic and technical imaginations." In Proceedings of the SIGCHI conference on human factors in computing systems, pp. 11451148. ACM, 2012.

54 Simonsen, Jesper, and Finn Kensing. "Using ethnography in contextual design." Communications of the ACM 40, no. 7 (1997): 82-88.

55 Millen, David R. "Rapid ethnography: time deepening strategies for HCI field research." In Proceedings of the 3rd conference on Designing interactive systems: processes, practices, methods, and techniques, pp. 280-286. ACM, 2000.

56 Barab, Sasha A., Michael K. Thomas, Tyler Dodge, Kurt Squire, and Markeda Newell. "Critical design ethnography: Designing for change." Anthropology \& Education Quarterly 35, no. 2 (2004): 254-268.

57 Bang, Megan, Douglas Medin, Karen Washinawatok, and Shannon Chapman. "Innovations in culturally based science education through partnerships and community." In New Science of Learning, pp. 569-592. Springer New York, 2010.

58 Penuel, William R., Samuel Severance, Raymond Johnson, Heather Leary, and Susan Miller. "The Emergence of New Objects in Co-Design: A Cultural-Historical Activity Theoretical Analysis." Proceedings of the 11th International Conference of the Learning Sciences, June 2014. Accessed April 12, 2016.

http://learndbir.org/resources/Negotiating the Object in_CoDesign.pdf.

59 Muller, Michael J., Daniel M. Wildman, and Ellen A. White. "Taxonomy of Participatory Design Practices." Posters and Short Talks of the 1992 SIGCHI Conference on Human Factors in Computing Systems - CHI '92, 1992. Accessed April 12, 2016. doi:10.1145/1125021.1125053.

60 Muller, Grudin, Jonathan, and John Pruitt. "Personas, participatory design and product development: An infrastructure for engagement." In PDC, pp. 144-152. 2002.

61 Schwaber, Ken, and Mike Beedle. Agile software development with Scrum. Vol. 1. Upper Saddle River: Prentice Hall, 2002.

62 Schwaber, Ken, and Jeff Sutherland. "The scrum guide." Scrum Alliance 21 (2011): 19.

63 Hammarberg, Marcus, and Joakim Sunden. Kanban in action. Manning Publications Co., 2014.

64 Anderson, David J. Kanban: successful evolutionary change for your technology business. Blue Hole Press, 2010.

65 Kniberg, Henrik, and Mattias Skarin. Kanban and Scrum-making the most of both. Lulu.com, 2010.

66 Hall, Erika. Just enough research. New York: A Book Apart, 2013.

67 Chisnell, Dana. 2020. "Project Redesign". National Conference On Citizenship. https://ncoc.org/projectredesign/.

68 Kirkpatrick, Donald, and James Kirkpatrick. Evaluating training programs: The four levels. Berrett-Koehler Publishers, 2006.

69 Kirkpatrick, Donald, and James Kirkpatrick. Transferring learning to behavior: Using the four levels to improve performance. Berrett-Koehler Publishers, 2005.

70 Kirkpatrick, Donald L. Implementing the four levels: A practical guide for effective evaluation of training programs: Easyread super large 24pt edition. ReadHowYouWant. com, 2009.

71 Watkins, Ryan, Doug Leigh, Rob Foshay, and Roger Kaufman. "Kirkpatrick plus: Evaluation and continuous improvement with a community focus." Educational Technology Research and Development 46, no. 4 (1998): 90-96.

72 Weinstein, Carol Simon. "The classroom as a social context for learning." Annual review of psychology 42, no. 1 (1991): 493-525.

73 Conway, James M., Elise L. Amel, and Daniel P. Gerwien. "Teaching and learning in the social context: A meta-analysis of service learning's effects on academic, personal, social, and citizenship outcomes." Teaching of psychology 36, no. 4 (2009): 233-245.

74 Hausfather, Samuel J. "Vygotsky and schooling: Creating a social context for learning." Action in teacher education 18, no. 2 (1996): 1-10. 
International Journal for Service Learning in Engineering, Humanitarian Engineering and Social Entrepreneurship Vol. 16, No. 1, pp. 58-89, Spring 2021

ISSN 1555-9033

75 Jarvis, Peter. Adult learning in the social context. Vol. 78. Routledge, 2011.

76 Coes, D. H. "Critically assessing the strengths and limitations of the Business Model Canvas." Master's thesis, University of Twente, 2014.

77 Blank, Steve. "The mission model canvas-an adapted business model canvas for mission-driven organizations." Steve Blank (2016).

78 "Subminimum Wage Employment for Workers with Disabilities." US Department of Labor Wage and Hour Division. US Department of Labor. Accessed December 23, 2020. https://www.dol.gov/agencies/whd/workerswith-disabilities.

79 "Back Pay." US Department of Labor. US Department of Labor. Accessed December 23, 2020. https://www.dol.gov/agencies/whd/workers-with-disabilities.

80 "Fact Sheet \#81: THE DAVIS-BACON WAGE SURVEY PROCESS." US Department of Labor Wage and Hour Division. US Department of Labor. Accessed December 23, 2020. https://www.dol.gov/agencies/whd/fact-sheets/81-DBRA-Surveys.

81 "Family and Medical Leave Act." US Department of Labor Wage and Hour Division. US Department of Labor. Accessed December 23, 2020. https://www.dol.gov/agencies/whd/fmla.

82 "Migrant and Seasonal Agricultural Worker Protection Act (MSPA)." US Department of Labor Wage and Hour Division. US Department of Labor. Accessed December 23, 2020.

https://www.dol.gov/agencies/whd/agriculture/mspa.

83 "Privacy Impact Assessment - WHD - WHISARD." US Department of Labor Wage and Hour Division. US Department of Labor. Accessed December 23, 2020. https://www.dol.gov/agencies/oasam/centersoffices/ocio/privacy/whd/whisard.

84 "Working with WIP limits for kanban." Atlassian Agile Coach. Atlassian. Accessed December 26, 2020. https://www.atlassian.com/agile/kanban/wip-limits. 